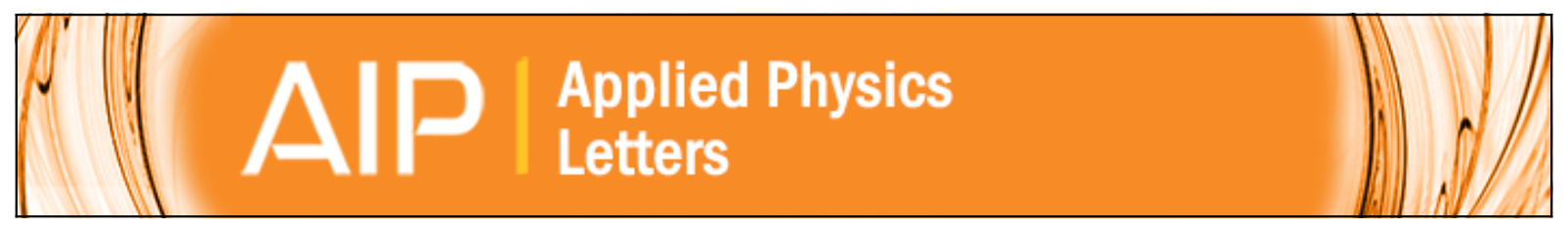

Oxygen transport and incorporation mechanisms in the dry thermal oxidation of $6 \mathrm{H}-\mathrm{SiC}$

C. Radtke, I. J. R. Baumvol, B. C. Ferrera, and F. C. Stedile

Citation: Applied Physics Letters 85, 3402 (2004); doi: 10.1063/1.1807033

View online: http://dx.doi.org/10.1063/1.1807033

View Table of Contents: http://scitation.aip.org/content/aip/journal/apl/85/16?ver=pdfcov

Published by the AIP Publishing

Articles you may be interested in

Interface trap passivation for Si O $2 /\left(0001^{-}\right)$C-terminated $4 \mathrm{H}-\mathrm{SiC}$

J. Appl. Phys. 98, 014902 (2005); 10.1063/1.1938270

Thermal oxidation of (0001) $4 \mathrm{H}-\mathrm{SiC}$ at high temperatures in ozone-admixed oxygen gas ambient Appl. Phys. Lett. 83, 884 (2003); 10.1063/1.1598621

Effect of oxidation and reoxidation on the oxide-substrate interface of $4 \mathrm{H}$ - and $6 \mathrm{H}-\mathrm{SiC}$ Appl. Phys. Lett. 77, 1437 (2000); 10.1063/1.1290490

Time dependence of the oxygen exchange $\mathrm{O} 2 \leftrightarrow \mathrm{SiO} 2$ at the SiO $2-\mathrm{Si}$ interface during dry thermal oxidation of silicon

J. Appl. Phys. 86, 1153 (1999); 10.1063/1.370858

Thermal decomposition of ultrathin oxide layers on $\mathrm{Si}(111)$ surfaces mediated by surface Si transport Appl. Phys. Lett. 70, 1095 (1997); 10.1063/1.118495

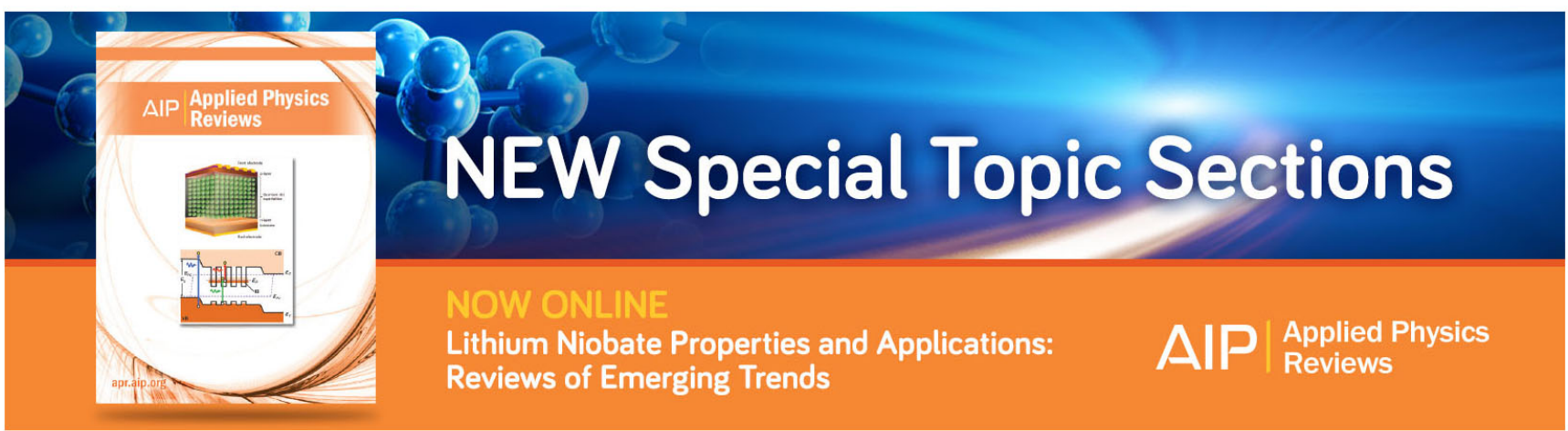




\title{
Oxygen transport and incorporation mechanisms in the dry thermal oxidation of $6 \mathrm{H}-\mathrm{SiC}$
}

\author{
C. Radtke \\ Commissariat à l'Energie Atomique, DSM-DRECAM-SPCSI-SIMA, Bâtiment 462, Saclay, \\ 91191 Gif sur Yvette Cedex, France \\ I. J. R. Baumvol \\ Centro de Ciências Exatas e Tecnológicas-UCS, Av. Francisco G. Vargas 1130, 95070-560, Caxias do Sul, \\ RS, Brazil \\ B. C. Ferrera and F. C. Stedile ${ }^{a)}$ \\ Instituto de Química, UFRGS, Avenida Bento Gonçalves 9500, 91509-900, Porto Alegre, RS, Brazil
}

(Received 26 April 2004; accepted 17 August 2004)

\begin{abstract}
Thermal oxidation of $6 \mathrm{H}-\mathrm{SiC}$ was investigated by means of isotopic tracing and narrow nuclear resonant reaction profiling techniques. The mechanisms of oxygen transport and incorporation were accessed by sequential oxidations in dry $\mathrm{O}_{2}$ enriched or not in the ${ }^{18} \mathrm{O}$ isotope and subsequent determinations of the ${ }^{18} \mathrm{O}$ profiles. After sequential ${ }^{16} \mathrm{O}_{2} /{ }^{18} \mathrm{O}_{2}$ or ${ }^{18} \mathrm{O}_{2} /{ }^{16} \mathrm{O}_{2}$ oxidations of $\mathrm{SiC}$, the ${ }^{18} \mathrm{O}$ profiles were seen to be markedly different from those observed in $\mathrm{Si}$ oxidation, which led to the identification of different mechanisms of oxygen incorporation and transport. The gradual nature of the $\mathrm{SiO}_{2} / \mathrm{SiC}$ interface was also evidenced by the ${ }^{18} \mathrm{O}$ depth distributions in samples oxidized in a single step in ${ }^{18} \mathrm{O}$-enriched $\mathrm{O}_{2}$. A probable explanation for this gradual $\mathrm{SiO}_{2} / \mathrm{SiC}$ interface is shown to be the formation of $\mathrm{C}$ clusters during oxidation. (C) 2004 American Institute of Physics. [DOI: $10.1063 / 1.1807033]$
\end{abstract}

$\mathrm{SiC}$ is a wide band gap semiconductor material, possessing desirable properties for devices operating in high temperature, high frequency, high power and/or high voltage conditions. Furthermore, $\mathrm{SiC}$ is the only compound semiconductor that can be thermally oxidized forming a film of $\mathrm{SiO}_{2}$, an outstanding dielectric material for device applications. Despite all these advantages, the electrical characteristics of devices built on $\mathrm{SiC}$ are worse than those prepared on $\mathrm{Si}$, mainly as a result of the detrimental properties of the formed $\mathrm{SiO}_{2} / \mathrm{SiC}$ interface. ${ }^{1}$ This fact hampers the wide utilization of this semiconductor in the fabrication of power devices. Aimed at improving the properties of the $\mathrm{SiO}_{2} / \mathrm{SiC}$ interface, different ways of growing the $\mathrm{SiO}_{2}$ layer ${ }^{2,3}$ and different postoxidation treatments ${ }^{4-7}$ have already been proposed. In order to achieve further improvement, fundamental knowledge of the mechanisms involved in thermal oxidation of $\mathrm{SiC}$ and the effects of each oxidation parameter (temperature, gas pressure, etc.) are of major importance. This knowledge will make it possible to modify conveniently the oxidation process and improve the electrical characteristics of the final device.

The structure and composition of the transition layer between $\mathrm{SiO}_{2}$ and $\mathrm{SiC}$ is still not as well understood as the $\mathrm{SiO}_{2} / \mathrm{Si}$ interface. The fundamental difference between these systems is the presence of $\mathrm{C}$ in the former. Investigations of thermal oxide growth on $\mathrm{SiC}$ indicate that, in the surface and bulk regions, the oxide is similar to that grown on $\mathrm{Si}^{1,8-10}$ whereas incompletely oxidized $\mathrm{C}$ and/or $\mathrm{Si}$ are found near the interface. ${ }^{1,3,11-13}$ Besides, the oxidation of $\mathrm{SiC}$ entails the production of carbonaceous species (mainly $\mathrm{CO}$ ) that diffuse through the oxide layer, giving rise to a new branch of possible reactions.
In the present work we investigate the atomic transport and incorporation of oxygen during thermal oxidation of $\mathrm{SiC}$, with special attention to the oxide/SiC transition region. These results are compared to those of similarly prepared $\mathrm{Si}$ samples, whose oxidation mechanisms are well established. The experiments consisted essentially of the sequential thermal growth of oxides in natural $\mathrm{O}_{2}\left({ }^{16} \mathrm{O}_{2}\right)$ and in $97 \%$ ${ }^{18} \mathrm{O}$-enriched $\mathrm{O}_{2}\left({ }^{18} \mathrm{O}_{2}\right)$, alternating the gas sequence, or performing oxidations only in ${ }^{18} \mathrm{O}_{2}$.

$6 \mathrm{H}-\mathrm{SiC}$ and $\mathrm{Si}(001)$ wafers were cleaned in a standard RCA routine, followed by a dip for $30 \mathrm{~s}$ in a $5 \% \mathrm{HF}$ aqueous solution, aimed at removing the native oxide, and water rinsing for $30 \mathrm{~s}$. All oxides were grown in a resistively heated quartz tube furnace under a static pressure of 100 mbar. ${ }^{18} \mathrm{O}$ profiles were determined by narrow nuclear resonant reaction profiling (NRP) using the resonance at $151 \mathrm{keV}$ in the crosssection curve of the ${ }^{18} \mathrm{O}(p, \alpha){ }^{15} \mathrm{~N}$ nuclear reaction. Profiles and excitation curves were normalized by the areal densities determined by nuclear reaction analysis and Rutherford backscattering spectrometry in channeling geometry. ${ }^{14}$

Figure 1(a) shows the excitation curves and the corresponding ${ }^{18} \mathrm{O}$ depth distributions in samples oxidized in two steps: ${ }^{16} \mathrm{O}_{2}$ at $1100{ }^{\circ} \mathrm{C}$ followed by ${ }^{18} \mathrm{O}_{2}$. The profile obtained for the $\mathrm{SiO}_{2} / \mathrm{Si}$ structure (dotted line) presents the well-known ${ }^{18} \mathrm{O}$-rich regions: erfc-like at the sample surface and box-like in the oxide/Si interface region. ${ }^{14}$ In the bulk of the oxide, the absence of ${ }^{18} \mathrm{O}$ in concentrations above its natural abundance $(0.2 \%)$ indicates that ${ }^{18} \mathrm{O}_{2}$ molecules in the second oxidation step diffuse through the already formed ${ }^{16} \mathrm{O}$-oxide without interacting with it, reacting with $\mathrm{Si}$ at an abrupt interface to form new $\mathrm{Si}^{18} \mathrm{O}_{2} .{ }^{15}$ The same sequential oxidations were performed on the $\mathrm{Si}$ face of the $\mathrm{SiC}$ wafers $(\mathrm{SiC}(0001))$. The ${ }^{18} \mathrm{O}$ profile in the sample reoxidized in ${ }^{18} \mathrm{O}_{2}$ at $950{ }^{\circ} \mathrm{C}$ (dash-dotted line) in the surface region is 

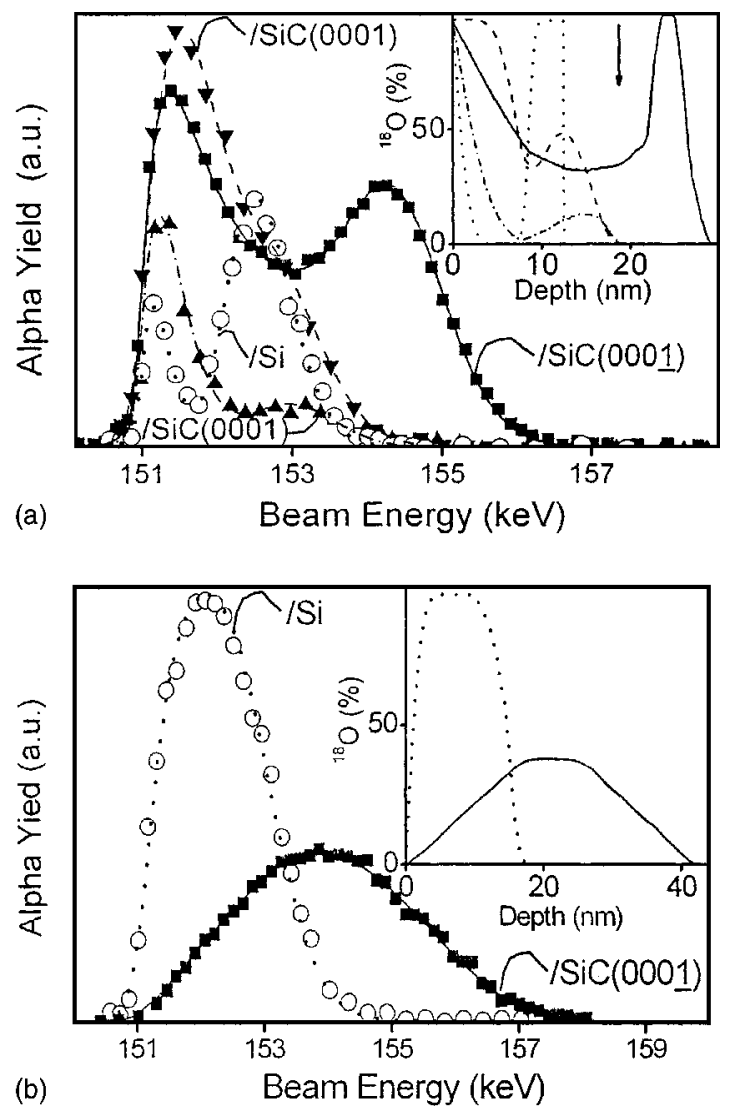

FIG. 1. Experimental excitation curves (symbols) of the ${ }^{18} \mathrm{O}(p, \alpha){ }^{15} \mathrm{~N}$ nuclear reaction and the corresponding simulations (lines) for silicon oxide films thermally grown on $\mathrm{Si}$ (001) (circles), $\mathrm{SiC}$ (0001) (triangles), and $\mathrm{SiC}$ (0001) (squares). The type of oxidized substrate is indicated. (a) Samples were first oxidized at $1100{ }^{\circ} \mathrm{C}$ in ${ }^{16} \mathrm{O}_{2}$ and then reoxidized in ${ }^{18} \mathrm{O}_{2}$ at $950{ }^{\circ} \mathrm{C}$ (circles and up triangles) or $1100{ }^{\circ} \mathrm{C}$ (squares and down triangles). The position of the $\mathrm{SiO}_{2} / \mathrm{SiC}$ interface after the first oxidation step of the $\mathrm{SiC}$ (0001) sample reoxidized at $950{ }^{\circ} \mathrm{C}$ (dash-dotted line) is indicated by an arrow. (b) Samples were first oxidized at $1100{ }^{\circ} \mathrm{C}$ in ${ }^{18} \mathrm{O}_{2}$ and then reoxidized in ${ }^{16} \mathrm{O}_{2}$ at $950{ }^{\circ} \mathrm{C}$ (circles) and $1100{ }^{\circ} \mathrm{C}$ (squares). ${ }^{18} \mathrm{O}$ profiles used for the simulations of excitation curves are shown in the respective insets with the same type of line of the respective simulations. ${ }^{18} \mathrm{O}$ concentration is normalized to $\mathrm{O}$ in stoichiometric $\mathrm{SiO}_{2}$. a.u. stands for arbitrary units.

erfc-like as in the case of Si. However, ${ }^{18} \mathrm{O}$ is also incorporated in the bulk of the oxide and in the interface region, where its concentration is only $13 \%$ and not equal to the isotopic labeling of the gas (97\%) as in the case of Si substrate. The position of the oxide/SiC interface in this sample, after the first oxidation step, is indicated by an arrow in Fig. 1(a). After the second oxidation, in ${ }^{18} \mathrm{O}_{2}$, the final thickness remains roughly the same. The ${ }^{18} \mathrm{O}$ profile in the $\mathrm{SiC}(0001)$ sample oxidized in the second step in ${ }^{18} \mathrm{O}_{2}$ at $1100{ }^{\circ} \mathrm{C}$ (dashed line) is also shown. The $\mathrm{SiO}_{2}$ layer grown in the first oxidation step was not sufficiently thick to clearly separate the surface and interface contributions of ${ }^{18} \mathrm{O}$. Besides, the amount of ${ }^{18} \mathrm{O}$ corresponding to the estimated interfacial peak is too small to allow for a study on how ${ }^{18} \mathrm{O}$ incorporates close to the $\mathrm{SiO}_{2} / \mathrm{SiC}$ interface. Thus, the oxidation of the $\mathrm{SiC}$ (0001) (or $\mathrm{C}$ face) was undertaken, because it has a higher oxidation rate, resembling more the Si oxidation rate than the one of $\mathrm{SiC}$ (0001). It enables the incorporation of higher amounts of ${ }^{18} \mathrm{O}$ in the interfacial region in reasonable oxidation times. The ${ }^{18} \mathrm{O}$ depth distribution of this sample is also shown (solid line). The ${ }^{18} \mathrm{O}$ interfacial peak in the case of the oxidized $\mathrm{C}$ face of the $\mathrm{SiC}$ sample evidences an ${ }^{18} \mathrm{O}$

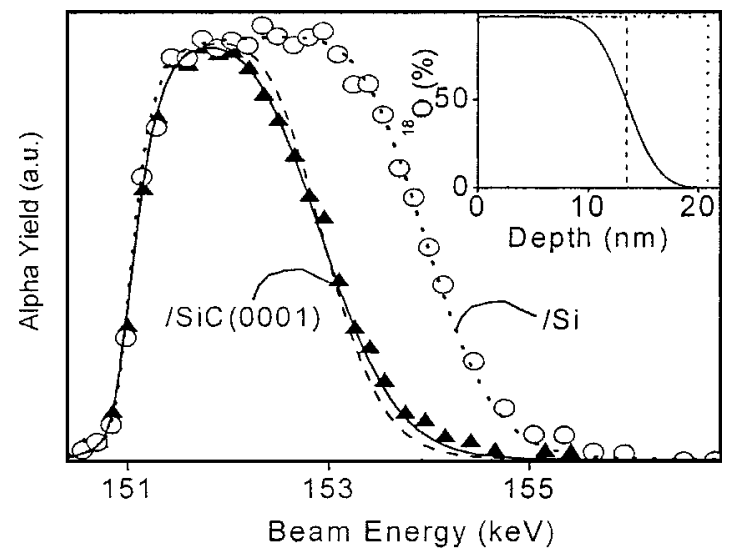

FIG. 2. Experimental excitation curves (symbols) of the ${ }^{18} \mathrm{O}(p, \alpha){ }^{15} \mathrm{~N}$ nuclear reaction and the corresponding simulations (lines) for silicon oxide films thermally grown on $\mathrm{SiC}$ (0001) (triangles) and on $\mathrm{Si} \mathrm{(001)} \mathrm{(circles).}$ The type of oxidized substrate is indicated. Oxidations were performed in ${ }^{18} \mathrm{O}_{2}$ at $1100{ }^{\circ} \mathrm{C}$. ${ }^{18} \mathrm{O}$ profiles used for the simulations of excitation curves are shown in the inset with the same type of line of the respective simulations. ${ }^{18} \mathrm{O}$ concentration is normalized to $\mathrm{O}$ in stoichiometric $\mathrm{SiO}_{2}$. a.u. stands for arbitrary units.

concentration that varies gradually at both sides of a narrow plateau of stoichiometric $\mathrm{Si}^{18} \mathrm{O}_{2}$ instead of the abrupt $\mathrm{Si}^{16} \mathrm{O}_{2} / \mathrm{Si}^{18} \mathrm{O}_{2}$ transition observed in the case of $\mathrm{Si}$. Besides, ${ }^{18} \mathrm{O}$ is also found in the bulk of the oxide film.

Figure 1(b) shows the ${ }^{18} \mathrm{O}$ profiles in $\mathrm{Si}$ and $\mathrm{SiC}(000 \underline{1})$ samples oxidized in the same way as the precedent ones but alternating the gas sequence: first oxidation in ${ }^{18} \mathrm{O}_{2}$ followed by ${ }^{16} \mathrm{O}_{2}$. ${ }^{18} \mathrm{O}$ is seen to occupy the sites analogous to those occupied by ${ }^{16} \mathrm{O}$ atoms in Fig. 1(a) and vice versa. In the case of the Si oxidized sample [dotted line in Fig. 1(b)], there is a rather abrupt transition between the bulk ${ }^{18} \mathrm{O}$-rich oxide and the near-interface ${ }^{16} \mathrm{O}$-oxide, evidencing that the first formed $\mathrm{Si}^{18} \mathrm{O}_{2}$ layer remained approximately unaltered after the second oxidation step. However, the ${ }^{18} \mathrm{O}$ profile obtained from the $\mathrm{SiC}$ oxidized sample is strikingly different in all film regions [solid line in Fig. 1(b)], evidencing an ${ }^{18} \mathrm{O}$ concentration in the bulk region much lower than the isotopic labeling of the ${ }^{18} \mathrm{O}_{2}$ gas, as well as the presence of a substantial amount of ${ }^{18} \mathrm{O}$ in the near-interface region, with a gradual transition between these two regions.

Figure 2 shows the ${ }^{18} \mathrm{O}$ profiles obtained from the $\mathrm{SiC}$ and $\mathrm{Si}$ samples oxidized in a single step in ${ }^{18} \mathrm{O}_{2}$. An abrupt interface between $\mathrm{SiO}_{2}$ and $\mathrm{Si}$ is observed (dotted line). However, in the case of the oxide/SiC interface the same box-like distribution (dashed line) did not lead to a satisfactory agreement between experimental data and the simulation curve. A good fit is only obtained if one assumes a graded interface (solid line). The gradual decrease of the ${ }^{18} \mathrm{O}$ concentration near the $\mathrm{SiO}_{2} / \mathrm{SiC}$ interface brings about the discussion on how the structure and/or composition of this interface as well as the reaction-diffusion phenomena involved in the oxidation of $\mathrm{SiC}$ could give rise to such a gradual transition. One could attribute it to interface roughness. However, this hypothesis was ruled out by high resolution TEM images. ${ }^{12}$ Alternatively, the presence of another element can lower the local O-concentration. Since the existence of a C-rich region close to the $\mathrm{SiO}_{2} / \mathrm{SiC}$ interface was shown by electron energy loss spectroscopy analysis, ${ }^{12}$ one may admit that the presence of $\mathrm{C}$ locally depletes the oxygen concentration and one observes the nonabrupt oxide/SiC in- 
(a)
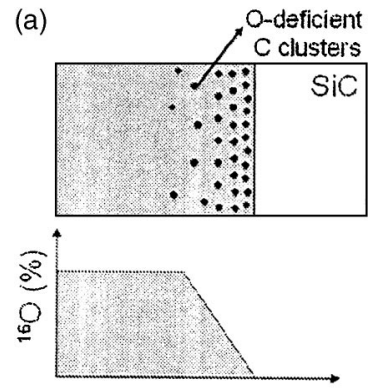

Depth (b) C clusters consumed
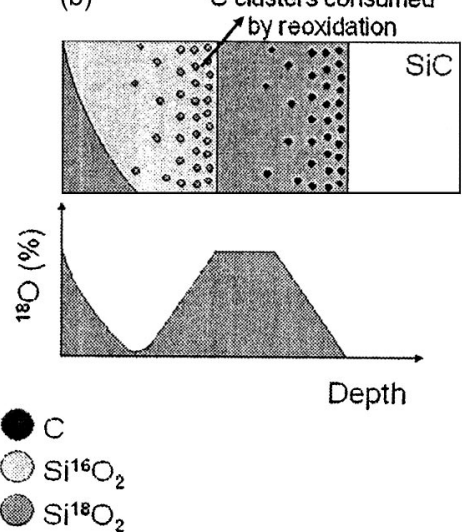

FIG. 3. Representation of a SiC sample submitted to sequential oxidations at high temperature: (a) after a first oxidation in ${ }^{16} \mathrm{O}_{2}$ and (b) after further oxidation in ${ }^{18} \mathrm{O}_{2}$. The resulting ${ }^{16} \mathrm{O}$ and ${ }^{18} \mathrm{O}$ profiles are represented, respectively.

terface as shown in Fig. 2. This phenomenon also leads to the different ${ }^{18} \mathrm{O}$ distributions observed in $\mathrm{SiC}$ samples as compared to those of $\mathrm{Si}$ in the interface region. In the case of $\mathrm{Si}$, there is no measurable mixture of oxygen incorporated in distinct oxidation steps, except for the oxide surface. In the case of $\mathrm{SiC}$, the results shown in Fig. 1 evidence a mixture of ${ }^{16} \mathrm{O}$ and ${ }^{18} \mathrm{O}$ from different oxidation steps also in the $\mathrm{SiO}_{2} / \mathrm{SiC}$ transition region. We propose that this mixture is intervened by the formation and consumption of $\mathrm{C}$ clusters during oxidation as represented pictorially in Fig. 3 .

Following this reasoning, $\mathrm{CO}$ molecules produced in the near-interface region by reaction of $\mathrm{O}_{2}$ with $\mathrm{SiC}$ will diffuse and may undergo further chemical reactions. Possible reactions of $\mathrm{CO}$ with the $\mathrm{SiO}_{2}$ network were investigated and nucleation and growth of $\mathrm{C}$ clusters in the oxide film and the emission of $\mathrm{CO}_{2}$ molecules was theoretically predicted. ${ }^{16}$ They also showed that these clusters can be consumed by their reaction with diffusing $\mathrm{O}_{2}$ molecules during oxidation. Thus, in the oxidation process, there is simultaneous formation of $\mathrm{C}$ clusters and their progressive consumption by reaction with $\mathrm{O}_{2}$, resulting in a depth distribution of $\mathrm{C}$ clusters that can be like the one shown in Fig. 3(a). The resulting oxygen profile is analogous to the solid line one in Fig. 2, obtained by oxidizing $\mathrm{SiC}$ in a single step. A second oxidation step in ${ }^{18} \mathrm{O}_{2}$ following a first step in ${ }^{16} \mathrm{O}_{2}$ will cause ${ }^{18} \mathrm{O}$ incorporation by: (i) the formation of new $\mathrm{Si}^{18} \mathrm{O}_{2}$ at the interface, (ii) the consumption of the carbon clusters, and (iii) isotopic exchange in the surface region. Mechanism (ii) is confirmed by the ${ }^{18} \mathrm{O}$ profile of the $\mathrm{SiC}$ sample oxidized first at $1100{ }^{\circ} \mathrm{C}$ in ${ }^{16} \mathrm{O}_{2}$ followed by oxidation at $950{ }^{\circ} \mathrm{C}$ in ${ }^{18} \mathrm{O}_{2}$ [dash-dotted line in Fig. 1(a)]. In this case, during the second, lower temperature oxidation step, the $\mathrm{CO}$ production is strongly diminished and, consequently, many less $\mathrm{C}$ clusters are formed. Therefore, ${ }^{18} \mathrm{O}$ incorporation is mostly a result of consumption of the $\mathrm{C}$ clusters already formed in the previously existing oxide layer. In fact, it is known that a low temperature reoxidation of the $\mathrm{SiO}_{2} / \mathrm{SiC}$ structure is responsible for a decrease in the density of electronic states of the $\mathrm{SiO}_{2} / \mathrm{SiC}$ interface, related to a reduction on the concentration of carbonaceous species. ${ }^{7}$ Performing a reoxidation (in ${ }^{18} \mathrm{O}_{2}$ ) at a higher temperature leads to, besides the consumption of the previously formed clusters, oxidation of the $\mathrm{SiC}$ substrate, creating a new layer of $\mathrm{Si}^{18} \mathrm{O}_{2}$ and forming new $\mathrm{C}$

clusters close to the new $\mathrm{SiO}_{2} / \mathrm{SiC}$ interface. The nearinterface ${ }^{18} \mathrm{O}$ distribution that emerges from this model is represented in Fig. 3(b). The solid line profile in Fig. 1(a), from an oxidized $\mathrm{SiC}$ (0001) sample, corroborates this idea.

A further test to the validity of this reasoning could be obtained by performing a low temperature reoxidation in ${ }^{18} \mathrm{O}_{2}$ of the $\mathrm{SiC}$ sample of Fig. 2. If the preceding model is valid, this procedure should transform the smooth decrease of the ${ }^{18} \mathrm{O}$ concentration observed before the reoxidation step to a more abrupt transition. In fact, this confirmation was achieved $^{17}$ using $\mathrm{x}$-ray photoelectron spectroscopy to observe the effect of a low temperature reoxidation in an effort to obtain a more abrupt $\mathrm{SiO}_{2} / \mathrm{SiC}$ interface. Nevertheless, we do not exclude the existence of other possible mechanisms that can contribute to the incorporation of ${ }^{18} \mathrm{O}$ in the already formed $\mathrm{Si}^{16} \mathrm{O}_{2}$ layer, like the ejection of $\mathrm{Si}$ interstitials from the substrate and ${ }^{16} \mathrm{O}-{ }^{18} \mathrm{O}$ isotopic exchange. ${ }^{18}$

In summary, based on the present findings this letter has identified different mechanisms through which oxygen is incorporated in the bulk and interface oxide regions during thermal oxidation of $\mathrm{SiC}$, namely consumption of carbon clusters and reaction with the $\mathrm{SiC}$ substrate in a wider region as compared to $\mathrm{Si}$ oxidation. The dynamics of these processes gives rise to different ${ }^{18} \mathrm{O}$ profiles. However, the present findings do not exclude the existence of other mechanisms that can also contribute to the final ${ }^{18} \mathrm{O}$ depth distributions. The abruptness of the $\mathrm{SiO}_{2} / \mathrm{SiC}$ interface was also investigated, evidencing that the formation of $\mathrm{C}$ clusters during oxidation is a probable explanation for the gradual nature of this interface. In order to get further insight into this subject, we intend to perform $\mathrm{C}$ depth profiling of these samples with secondary ion mass spectrometry and NRP techniques.

\footnotetext{
${ }^{1}$ V. V. Afanas'ev, M. Bassler, G. Pensl, and A. Stesmans, Mater. Sci. Forum 389-393, 961 (2002).
}

${ }^{2}$ G. Lucovsky, H. Niimi, A. Golz, and H. Kurz, Appl. Surf. Sci. 123, 435 (1998).

${ }^{3}$ F. Amy, P. Soukiassian, Y. K. Hwu, and C. Brylinski, Phys. Rev. B 65, 165323 (2002)

${ }^{4}$ G. Chung, C.C. Tin, J.R. Williams, K. McDonald, M. Di Ventra, R.K. Chanana, S. T.Pantelides, L.C. Feldman, and R.A. Weller, Appl. Phys. Lett. 77, 3601 (2000).

${ }^{5}$ R. Schorner, P. Friedrichs, D. Peters, D. Stephani, S. Dimitrijev, and P. Jamet, Appl. Phys. Lett. 80, 4253 (2002).

${ }^{6}$ K. Y. Cheong, S. Dimitrijev, J.S. Han, and H.B. Harrison, J. Appl. Phys. 93, 5682 (2003).

${ }^{7}$ A. Ekoué, O. Renault, T. Billon, L. Di Cioccio, and G. Guillot, Mater. Sci. Forum 433-436, 555 (2003).

${ }^{8}$ M. B. Johnson, M. E. Zvanut, and O. Richardson, J. Electron. Mater. 29, 368 (2000).

${ }^{9}$ K. McDonald, M. B. Huang, R. A. Weller, L. C. Feldman, J. R. Williams, F.C. Stedile, I. J. R. Baumvol, and C. Radtke, Appl. Phys. Lett. 76, 568 (2000).

${ }^{10}$ I.C. Vickridge, I. Trimaille, J.-J. Ganem, S. Rigo, C. Radtke, I.J.R. Baumvol, and F.C. Stedile, Phys. Rev. Lett. 89, 256102 (2002).

${ }^{11}$ C. Virojanadara and L.I. Johansson, Surf. Sci. 472, L145 (2001).

${ }^{12}$ K.C. Chang, N.T. Nuhfer, L.M. Porter, and Q. Wahab, Appl. Phys. Lett. 77, 2186 (2000)

${ }^{13}$ C. Radtke, I. J. R. Baumvol, J. Morais, and F. C. Stedile, Appl. Phys. Lett. 78, 3601 (2001)

${ }^{14}$ I. J. R. Baumvol, Surf. Sci. Rep. 36, 1 (1999).

${ }^{15}$ B.E. Deal and A.S. Grove, J. Appl. Phys. 36, 3770 (1965).

${ }^{16}$ S. Wang, M. Di Ventra, S.G. Kim, and S.T. Pantelides, Phys. Rev. Lett. 86, 5946 (2001)

${ }^{17}$ G.G. Jernigan, R. E. Stahlbush, and N. S. Saks, Appl. Phys. Lett. 77, 1437 (2000).

${ }^{18}$ I. Trimaille, J.-J. Ganem, I.C. Vickridge, S. Rigo, G. Battistig, E. Szilagyi, I.J.R. Baumvol, C. Radtke, and F.C. Stedile, Nucl. Instrum. Methods Phys. 